\title{
Circadian Rhythms of Melatonin Secretion in Peri- and Postmenopausal Women with Insomnia
}

\author{
Irina M. Madaeva, PhD, ScD*; Natalya V. Semenova, PhD; Elena I. Solodova, MD; \\ Sergey I. Kolesnikov, Academician of the RAS; Rajana Zhambalova, MD; \\ Lubov I. Kolesnikova, Academician of the RAS \\ Scientific Center of Family Health Problems and Human Reproduction \\ Irkutsk, the Russian Federation
}

\begin{abstract}
The aim of this study was to assess complaints about sleep quality and to investigate circadian rhythms of melatonin secretion in peri- and postmenopausal women.

Material and Methods: A total of 146 climacteric women were examined. All patients were divided into 2 groups: Group1 included 72 perimenopausal women and Group 2 included 74 postmenopausal women. Women were surveyed with special questionnaires: PSQI, FFS, ESS, Daytime Feeling and Functioning Scale. Insomnia Severity Index (ISI) was calculated. Salivary melatonin content was determined (4 times a day) by immunoassay using Microplate Reader EL $\times 808$ (USA).

Results: Perimenopausal women often complained about difficulties falling asleep (more than 20 minutes from the moment the light was turned off) and difficulties awakening in the morning, while postmenopausal women often complained about snoring and frequent awakenings during sleep ( $\geq 2$ times). ISI was $21.3 \pm 0.54$ in Group 1 and $24.8 \pm 0.31$ in Group 2, which corresponded to insomnia. Daily melatonin secretion in perimenopausal patients with insomnia was altered - the maximal level was registered in the morning hours. The circadian rhythms of melatonin secretion in the group of postmenopausal women did not correlate to the occurrence of insomnia.

Conclusion: We can recommend administration of melatonin in the evening time and light therapy in the early morning hours in the complex treatment of sleep disprders in perimenopausal women for normalizing and shifting the chronobiological rhythms of melatonin secretion, and specific therapy is aimed to eliminate snoring for postmenopausal women. (International Journal of Biomedicine. 2017;7(2):126-130.)
\end{abstract}

Key words: melatonin $\bullet$ circadian rhythms $\bullet$ perimenopause $\bullet$ postmenopause $\bullet$ insomnia

\section{Abbreviations}

BW, body weight; BMI, body mass index; ESS, Epworth Sleepiness Scale; FFS, Flinders Fatigue Scale; ISI, Insomnia Severity Index; PSQI, Pittsburgh Sleep Quality Index; SDs, sleep disorders.

\section{Introduction}

The climacteric is a transition period from the reproductive phase to its extinction and a cessation of menstrual and genital function: follicular reserve of ovaries depletion,

*Corresponding author: Irina M. Madaeva, PhD, ScD. The Chief of Somnological Center, Scientific Center of Family Health Problems and Human Reproduction.Irkutsk, Russia.E-mail:nightchild@mail.ru decrease in ovarian activity, changes in relationships between hormones, and decrease in estrogen level. ${ }^{(1)}$ Of menopausal women, $60 \%-80 \%$ have vegetovascular, mental and metabolic disorders. One of the main signs of neurovegetative changes in climacteric women is the presence of sleep disorders (SDs). ${ }^{(2,3)}$ Some studies have shown that SDs are reported by $39 \%-47 \%$ of perimenopausal women and 35\%-60\% of postmenopausal women. ${ }^{(3)}$ The role of the regulator of circadian rhythms has been assigned to the melatonin 
hormone. ${ }^{(4)}$ The cells producing this hormone are found in the pineal gland, retina, tract, urogenital system, and thymus. In healthy people, the melatonin level begins to increase in the evening when the level of illumination decreases. The pineal gland receives information about external light through complex nervous pathways, with a relay in the suprachiasmatic nuclei of the hypothalamus. At night, in darkness, when the majority of neurons in suprachiasmatic nuclei are inactive, nerve terminals excrete norepinephrine, which activates melatonin-generating enzymes in pinealocytes. ${ }^{(5)}$ The agerelated decrease in melatonin secretion is a well-known fact; not only its level but also its production curve changes. (6-8) These changes could be the cause of various diseases, including SDs. ${ }^{(9)}$

Results of our pilot research show that there is a relationship between the chronobiological rhythms of melatonin secretion and SDs in women of perimenopausal age. ${ }^{(10)}$ The studies on age-related changes in melatonin level in women during various phases of the climacteric, and the effect of those changes on the appearance of SDs, is at the present time of great interest. This area of investigation makes it possible to elaborate the main principles of pathogenic therapy for certain SDs in climacteric women and a range of medical and social measures to conserve health and life quality in these women.

The aim of this study was to assess complaints about sleep quality and to investigate circadian rhythms of melatonin secretion in peri- and postmenopausal women.

\section{Material and Methods}

The study was approved by the Scientific Center of Family Health Problems and Human Reproduction Ethics Committee. Written informed consent was obtained from each patient.

A total of 146 climacteric women were examined. All patients were divided into 2 groups: Group1 included 72 perimenopausal women and Group 2 included 74 postmenopausal women.

Inclusion criteria for Group 1 were age 45-55; oligomenorrhoea or amenorrhea during last 12 months; ultrasounds criteria: 1) endometrial dysfunction: mismatch of structure and thickness corresponding to the first and the second phases of the menstrual cycle; 2) ovarian follicle reserve depletion

Inclusion criteria for Group 2 were age 56-60; amenorrhea $\geq 12$ months; FSH level $>20 \mathrm{iU} / \mathrm{ml}$, index LH/FSH $<1$; ultrasounds criteria: 1) thin nonfunctional endometrium, endometrial echo thinner than $5 \mathrm{~mm}$; 2) lack of ovarian follicle reserve.

Exclusion criteria for both groups were hormone replacement therapy; decompensation of cardiovascular, mental, neurological, and endocrine diseases; an exacerbation of chronic diseases; presence of chronic SDs in the past; hypnotics administration during the last two weeks; surgical menopause; work in shifts.

After questioning, the each group was divided into 2 subgroups: the main (insomnia+) and control (insomnia-). Women were surveyed with special questionnaires: PSQI, ${ }^{(11)}$
FFS, ${ }^{(12)}$ ESS, ${ }^{(13)}$ Daytime Feeling and Functioning Scale. ${ }^{(14)}$ Insomnia Severity Index (ISI) ${ }^{(15)}$ was calculated.

Questioning showed that $54.2 \%$ of perimenopausal and $40.5 \%$ of postmenopausal women did not have SDs. They were assigned to the control group. Basic characteristics, including age, height, BW, BMI are shown in Table 1. There were no differences in the characteristics of the control and insomnia group in perimenopause. At the same time, during postmenopause BW and BMI increased significantly in the group with insomnia compared to the control.

Table 1.

Clinical characteristics of patients.

\begin{tabular}{|c|c|c|c|c|c|}
\hline \multirow{3}{*}{ 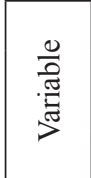 } & \multicolumn{2}{|c|}{ Perimenopause } & \multicolumn{2}{|c|}{ Postmenopause } & \multirow{3}{*}{ P-value } \\
\hline & $\begin{array}{c}\text { Insomnia- } \\
(\mathrm{n}=39)\end{array}$ & $\begin{array}{c}\text { Insomnia }+ \\
\quad(n=33)\end{array}$ & $\begin{array}{c}\text { Insomnia- } \\
(\mathrm{n}=30)\end{array}$ & $\begin{array}{c}\text { Insomnia }+ \\
(n=44)\end{array}$ & \\
\hline & 1 & 2 & 3 & 4 & \\
\hline Age, y & $50.36 \pm 3.05$ & $49.85 \pm 3.03$ & $56.25 \pm 3.97$ & $56.7 \pm 3.61$ & $\begin{array}{l}\mathrm{p}_{1-3}=0.000 \\
\mathrm{p}_{2-4}=0.000\end{array}$ \\
\hline $\begin{array}{l}\text { Height, } \\
\mathrm{cm}\end{array}$ & $164.19 \pm 5.31$ & $163.14 \pm 2.92$ & $163.41 \pm 5.47$ & $162.20 \pm 3.90$ & - \\
\hline $\begin{array}{l}\text { BW, } \\
\mathrm{kg}\end{array}$ & $70.12 \pm 11.72$ & $73.38 \pm 13.54$ & $74.66 \pm 13.64$ & $85.25 \pm 12.83$ & $\begin{array}{l}\mathrm{p}_{2-4}=0.000 \\
\mathrm{p}_{3-4}=0.001\end{array}$ \\
\hline $\begin{array}{l}\mathrm{BMI}, \\
\mathrm{kg} / \mathrm{m}^{2}\end{array}$ & $25.9 \pm 4.73$ & $27.09 \pm 1.56$ & $28.0 \pm 2.35$ & $34.15 \pm 1.5$ & $\begin{array}{l}\mathrm{p}_{1-3}=0.029 \\
\mathrm{p}_{2-4}=0.000 \\
\mathrm{p}_{3-4}=0.000\end{array}$ \\
\hline GD & $1(2.56 \%)$ & $10(30.3 \%)$ & $13(43.3 \%)$ & $17(38.6 \%)$ & $\begin{array}{l}\mathrm{p}_{1-2}=0.008 \\
\mathrm{p}_{1-3}=0.002\end{array}$ \\
\hline USD & $2(5.12 \%)$ & $3(9.09 \%)$ & $2(6.67 \%)$ & $13(29.5 \%)$ & $\begin{array}{l}\mathrm{p}_{2-4}=0.031 \\
\mathrm{p}_{3-4}=0.012\end{array}$ \\
\hline $\mathrm{OP}$ & $12(30.8 \%)$ & $19(57.6 \%)$ & $10(30.33 \%)$ & $36(81.8 \%)$ & $\mathrm{p}_{3-4}=0.049$ \\
\hline CVD & - & $7(21.2 \%)$ & $5(16.7 \%)$ & $10(22.7 \%)$ & $\begin{array}{l}\mathrm{p}_{1-2}=0.019 \\
\mathrm{p}_{1-3}=0.048\end{array}$ \\
\hline $\mathrm{T} 2 \mathrm{D}$ & - & $2(6.06 \%)$ & $1(3.33 \%)$ & $1(2.27 \%)$ & - \\
\hline TD & $5(12.8 \%)$ & $13(39.4 \%)$ & $8(26.7 \%)$ & $13(29.5 \%)$ & $\mathrm{p}_{1-2}=0.049$ \\
\hline PCOS & - & $1(3.03 \%)$ & $1(3.33 \%)$ & - & - \\
\hline UF & $13(3.33 \%)$ & $20(60.6 \%)$ & $9(30.0 \%)$ & $35(79.5 \%)$ & $\mathrm{p}_{3-4}=0.041$ \\
\hline EM & $4(10.26 \%)$ & $7(21.21 \%)$ & $2(6.67 \%)$ & $7(15.9 \%)$ & - \\
\hline
\end{tabular}

PCOS- Polycystic Ovary Syndrome, T2D - Type 2 diabetes, GD Gastrointestinal disease, USD - Urinary system disorders, CVD Cardiovascular disease, EM - Endometriosis, TD- Thyroid disease, UF- Uterine fibroids

To determine melatonin level, non-stimulated saliva was collected strictly at a fixed time 4 times a day (6 a.m. -7 a.m., 12 p.m. - 1 p.m., 6 p.m. -7 p.m., 11 p.m. - 12 a.m.) into a special $2 \mathrm{ml}$ capsule, immediately frozen, and stored at $-20^{\circ} \mathrm{C}$. Melatonin content was determined by immunoassay using Microplate Reader EL×808 (USA). Salivary melatonin levels were expressed in $\mathrm{pg} / \mathrm{mL}$.

Statistical analysis was performed using STATISTICA 6.1 software (Stat-Soft Inc., USA). For descriptive analysis, results are presented as mean \pm standard deviation (SD), median, interquartile range (IQR; 25 th to 75 th percentiles). For data with normal distribution, inter-group comparisons were 
performed using Student's t-test. Differences of continuous variables departing from the normal distribution were tested by the Mann-Whitney $U$-test. Categorical variables were analyzed using the Chi square test. A probability value of $\mathrm{P}<0.05$ was considered statistically significant.

\section{Results}

Perimenopausal women often complained about difficulties falling asleep (more than 20 minutes from the moment the light was turned off) and difficulties awakening in the morning, while postmenopausal women often complained about snoring and frequent awakenings during sleep $(\geq 2$ times) (Table 2). ISI was $21.3 \pm 0.54$ in Group 1 and $24.8 \pm 0.31$ in Group 2, which corresponded to insomnia.

Table 2.

Basic sleep problems in menopausal women (results of questioning)

\begin{tabular}{|l|c|c|c|}
\hline Complaint & $\begin{array}{c}\text { Perimenopausal } \\
\text { women (n=33) }\end{array}$ & $\begin{array}{c}\text { Postmenopausal } \\
\text { women (n=44) }\end{array}$ & P-value \\
\hline Falling asleep difficulties & $31(93.9 \%)$ & $15(34.1 \%)$ & 0.000 \\
\hline $\begin{array}{l}\text { Frequent awakenings } \\
\text { during sleep }\end{array}$ & $12(36.4 \%)$ & $28(63.6 \%)$ & 0.043 \\
\hline $\begin{array}{l}\text { Morning awakenings } \\
\text { difficulties }\end{array}$ & $26(78.8 \%)$ & $13(29.5 \%)$ & 0.000 \\
\hline Snoring (sleep apnea) & $7(21.2 \%)$ & $20(45.5 \%)$ & 0.049 \\
\hline $\begin{array}{l}\text { Excessive daytime } \\
\text { sleepiness }\end{array}$ & $7(21.2 \%)$ & $20(45.5 \%)$ & 0.049 \\
\hline Restless legs syndrome & $3(9.1 \%)$ & $6(13.6 \%)$ & 0.796 \\
\hline
\end{tabular}

Melatonin levels in climacteric women without insomnia are presented in Table 3. In subgroups without insomnia, postmenopausal women had significantly lower daytime and nighttime melatonin secretion than perimenopausal ones.

The highest melatonin level in perimenopausal women from the control group was during the night hours; the level decreased during the morning hours and then tended to increase in the daytime and in the evening (Table 3). Daily melatonin secretion in perimenopausal patients with insomnia was altered - the maximal level was registered in the morning hours. A comparison of the two groups showed that in women with insomnia, the melatonin level in the daytime, in the evening, and at night was below that of the control group by 2.2( $(\mathrm{P}<0.05), 2.3(\mathrm{P}<0.05)$ and 1.3 times, respectively. However, in the morning these women had a 1.5 times $(\mathrm{P}<0.05)$ higher melatonin level than the control group (Fig. 1).

The circadian rhythms of melatonin secretion in the group of postmenopausal women did not correlate to the occurrence of insomnia. Postmenopausal women from the control group had the peak of melatonin secretion during morning hours, while melatonin concentration during the daytime and in the evening decreased. A similar tendency in melatonin secretion was observed in postmenopausal patients with insomnia (Fig. 2).
Table 3.

Melatonin levels in peri- and postmenopausal women with or without insomnia

\begin{tabular}{|c|c|c|c|c|c|}
\hline \multirow[t]{4}{*}{ Variable } & \multicolumn{2}{|c|}{ Perimenopause } & \multicolumn{2}{|c|}{ Postmenopause } & \multirow{4}{*}{ P-value } \\
\hline & $\begin{array}{c}\text { Insomnia- } \\
(\mathrm{n}=39)\end{array}$ & $\begin{array}{c}\text { Insomnia+ } \\
(\mathrm{n}=33)\end{array}$ & $\begin{array}{c}\text { Insomnia- } \\
(\mathrm{n}=30)\end{array}$ & $\begin{array}{c}\text { Insomnia+ } \\
(\mathrm{n}=44)\end{array}$ & \\
\hline & (1) & (2) & (3) & (4) & \\
\hline & \multicolumn{4}{|c|}{$\begin{array}{c}\text { Mean } \pm \text { SD } \\
\text { Median } \\
25^{\text {th }}-75^{\text {th }} \text { percentile }\end{array}$} & \\
\hline $\begin{array}{l}\text { Melatonin } \\
6 \text { a.m.- } \\
7 \text { a.m., } \\
\text { pg/ml }\end{array}$ & $\begin{array}{l}6.86 \pm 4.42 \\
6.86 \\
2.79-8.46\end{array}$ & $\begin{array}{c}10.52 \pm 6.20 \\
10.07 \\
6.02-11.25\end{array}$ & $\begin{array}{c}11.02 \pm 8.16 \\
9.80 \\
3.88-16.86\end{array}$ & $\begin{array}{c}9.54 \pm 8.49 \\
7.12 \\
3.33-9.83\end{array}$ & $\mathrm{p}_{1-2}=0.011$ \\
\hline $\begin{array}{l}\text { Melatonin } \\
12 \text { p.m.- } \\
1 \text { p.m., } \\
\text { pg/ml }\end{array}$ & $\begin{array}{c}4.91 \pm 3.36 \\
5.71 \\
1.64-8.93\end{array}$ & $\begin{array}{c}2.27 \pm 1.59 \\
2.34 \\
0.82-3.14\end{array}$ & $\begin{array}{c}2.21 \pm 1.16 \\
2.39 \\
1.43-2.61\end{array}$ & $\begin{array}{c}3.60 \pm 3.78 \\
2.56 \\
0.94-5.27\end{array}$ & $\begin{array}{l}\mathrm{p}_{1-2}=0.031 \\
\mathrm{p}_{1-3}=0.021\end{array}$ \\
\hline $\begin{array}{l}\text { Melatonin } \\
6 \text { p.m.- } \\
7 \text { p.m., } \\
\text { pg/ml }\end{array}$ & $\begin{array}{c}4.94 \pm 5.20 \\
4.92 \\
1.35-5.44\end{array}$ & $\begin{array}{c}2.12 \pm 2.21 \\
1.32 \\
0.52-2.40\end{array}$ & $\begin{array}{c}1.42 \pm 1.30 \\
1.22 \\
0.43-2.20\end{array}$ & $\begin{array}{c}2.02 \pm 1.79 \\
1.38 \\
0.88-2.45\end{array}$ & $\begin{array}{l}\mathrm{p}_{1-2}=0.009 \\
\mathrm{p}_{1-3}=0.000 \\
\mathrm{p}_{1-4}=0.022\end{array}$ \\
\hline $\begin{array}{l}\text { Melatonin } \\
11 \text { p.m - } \\
12 \text { a.m., } \\
\text { pg/ml }\end{array}$ & $\begin{array}{c}10.03 \pm 7.38 \\
9.51 \\
6.40-10.67\end{array}$ & $\begin{array}{l}7.97 \pm 5.07 \\
7.97 \\
3.88-9.53\end{array}$ & \begin{tabular}{|c|}
$5.66 \pm 2.25$ \\
6.08 \\
$3.77-7.30$
\end{tabular} & $\mid \begin{array}{c}8.29 \pm 6.59 \\
8.02 \\
5.28-8.79\end{array}$ & $\mathrm{p}_{1-3}=0.008$ \\
\hline
\end{tabular}

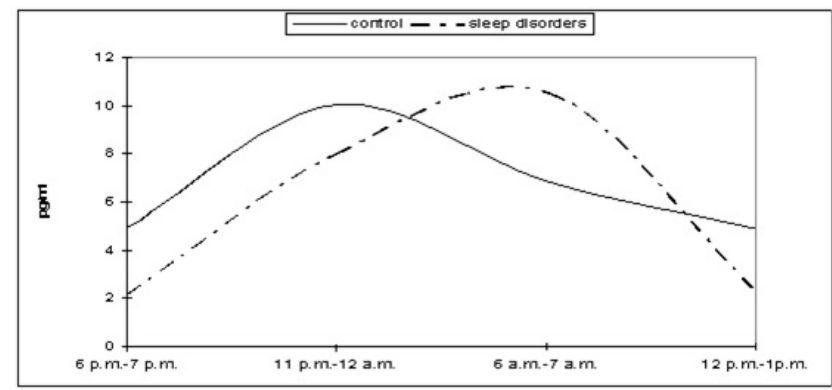

Fig. 1. Circadian rhythms of melatonin secretion in perimenopausal women with or without insomnia

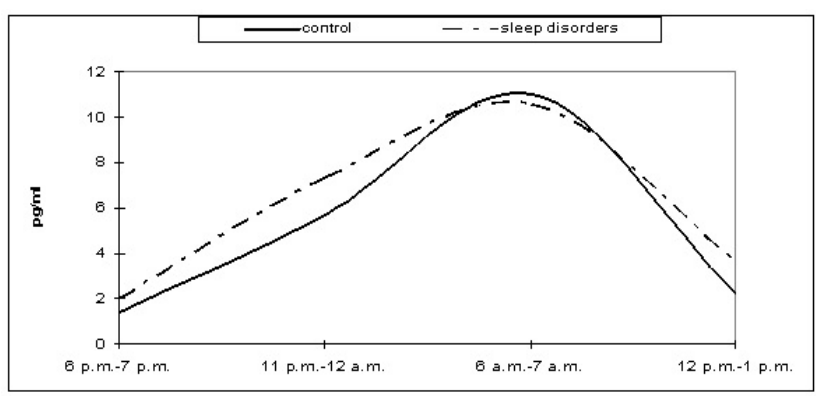

Fig. 2. Circadian rhythms of melatonin secretion in postmenopausal women with or without insomnia

\section{Discussion}

Some studies have shown an age-related decrease in the concentration of melatonin at the night peak. ${ }^{(6,16,17)}$ This fact 
indicates a decrease in those epiphysis functions that produce melatonin, which is a consequence of functional changes in the pineal gland and other links of the circadian system of the organism in the process of aging. ${ }^{(18)}$ An age-related decrease in melatonin secretion is indicative of impaired pineal and pituitary control over ovarian rhythm and a progressive decline in fertility function. ${ }^{(19)}$ It has been found that older females have significantly lower urinary 6-sulfatoxymelatonin than older males. ${ }^{(20)}$ The results of some studies have demonstrated that melatonin and estrogens act on the feedback principle. ${ }^{(2)}$

LI Mal'tseva et al. ${ }^{(21)}$ showed a decrease in melatonin level in most climacteric women that depended on menopause severity. However, changes in perimenopausal women were ambiguous and the melatonin level was increased in $13 \%$ of patients. Toffol et al. ${ }^{(22)}$ examined how the serum melatonin concentrations in perimenopausal and postmenopausal women influence mood, sleep, vasomotor symptoms, and quality of life. It was shown that postmenopausal women had lower nighttime serum melatonin concentrations than perimenopausal women. The duration of melatonin secretion was shorter in postmenopausal women, whereas melatonin peak time did not differ. ${ }^{(22)}$ The results of another study showed that nocturnal serum melatonin secretion in premenopausal women declined moderately from 17 to 45 years of age, and increased in the period from 46 to 50 years of age. Among postmenopausal women, a steep, agerelated decline in nocturnal melatonin secretion was found for up to 15 years postmenopause, followed by an extremely gradual decline thereafter. ${ }^{(23)}$ Waleca-Kapic et al. ${ }^{(24)}$ found a negative correlation between urinary 6-sulfatoxymelatonin excretion and BMI in overweight postmenopausal women, which confirms the influence of melatonin on metabolism.

The relationship between melatonin secretion and SDs has been shown in many studies. ${ }^{(8,9,25,26)}$ Thus, it was shown that in climacteric women insomnia was accompanied by a decreased melatonin level in blood serum. ${ }^{(26)}$ Our data give some new insight into the role of melatonin in SDs of menopausal women. We found that the circadian rhythm of melatonin secretion in perimenopausal women with SDs is disrupted. Similar results were obtained by Parry et al., who studied the relationship between melatonin, menopausal depression, and sleep end time. According to the authors, the increased melatonin secretion that is phase delayed into the morning characterized menopausal depressed patients. ${ }^{(9)}$ The authors suggested that higher melatonin levels or delayed offset in depressed patients might be caused by a long duration of sleep in women who may be trying to compensate for sleep disturbances.

In addition, we showed that peak melatonin secretion in postmenopausal women with and without SDs is registered in the early morning hours. Probably, changes in timing of the melatonin rhythm during postmenopause does not play a causal role in sleep disruption. Similar findings were suggested by Duffy et al., ${ }^{(27)}$ who investigated the relationship between sleep timing and melatonin circadian rhythm in young and older subjects without sleep complaints. The relationship between plasma melatonin rhythm and sleep time was such that the older subjects were sleeping and waking earlier relative to their nightly melatonin secretory episode. Consequently, the older subjects were waking at a time when they had higher relative melatonin levels, in contrast to younger subjects, whose melatonin levels were relatively lower by the time they woke up. However, the relationship between melatonin rhythms and sleep in subjects with sleep disorders was not investigated.

\section{Conclusion}

According to our results, nearly half of perimenopausal and more than half postmenopausal women have insomnia. Our findings suggest that insomnia in perimenopausal women is associated with altered $24 \mathrm{~h}$ melatonin secretion that is characterized by a shift of the peak secretion from nighttime to the early morning hours, while there is a tendency for melatonin levels to decrease in postmenopausal women. Based on our study results, we can recommend administration of melatonin in the evening time and light therapy in the early morning hours in the complex treatment of SDs in perimenopausal women for normalizing and shifting the chronobiological rhythms of melatonin secretion, and specific therapy is aimed to eliminate snoring for postmenopausal women.

\section{Competing interests}

The authors declare that they have no competing interests.

\section{Acknowledgments}

This study was supported by the Russian Foundation for Basic Research, research project No. 16-34-00093.

\section{References}

1. Hale GE, Robertson DM, Burger HG. The perimenopausal women: endocrinology and management. J Steroid Biochem Mol Biol. 2013; 142:121-31. doi: 10.1016/j. jsbmb.2013.08.015.

2. $\mathrm{Xu} \mathrm{Q}$, Lang CP. Examining the relationship between subjective sleep disturbance and menopause: a systematic review and meta-analysis. Menopause. 2014; 21(12):1301-18. doi: 10.1097/GME.0000000000000240.

3. Madaeva IM, Kolesnikova LI, Solodova EI, Semenova NV. [Menopause and sleep disturbances]. Bulletin of the East Siberian Scientific Center SBRAMS. 2012. (2.2):173-7. [Article in Russian].

4. Sack R, Auckley D, Auger R, Carskadon M, Wright K, Vitiello M, Zhdanova IV; American Academy of Sleep Medicine. Circadian rhythm sleep disorders: part II, advanced sleep phase disorder, delayed sleep phase disorder, freerunning disorder, and irregular sleep-wake rhythm. An American Academy of Sleep Medicine review. Sleep. 2007; 30(11):1484-501.

5. Zee PC, Manthena P. The brain's master circadian clock: implications and opportunities for therapy of sleep disorders. Sleep Med Rev. 2007;11(1):59-70.

6. Magri F, Sarra S, Cinchetti W, Guazzoni V, Fioravanti M, 
Cravello L, Ferrary E. Qualitative and quantitative changes of melatonin levels in phsysiological and pathological aging and in centenarians. Pineal Res. 2004; 36(4): 256-61.

7. Korkushko OV, Lapin BA, Goncharova ND, Khavinson VKh, Shatilo VB, Vengerin AA, Antoniuk-Shcheglova IA, Magdich LV. [Normalizing effect of the pineal gland peptides on the daily melatonin rhythm in old monkeys and elderly people]. Adv Gerontol. 2007;20(1):74-85. [Article in Russian]. 8. Meliska C, Martinez L, Lopez A, Sorenson D, Nowakowski S, Parry B. Relationship of morningnesseveningness questionnaire score to melatonin and sleep timing, body mass index and atypical depressive symptoms in peri- and post-menopausal women. Psychiatry Res. 2011; 188(1):88-95. doi: 10.1016/j.psychres.2010.12.010.

9. Parry B, Meliska C, Sorenson D, Lopez A, Martinez L, Nowakowski S, et al. Increased melatonin and delayed offset in menopausal depression: role of years past menopause, follicle-stimulating hormone, sleep end time, and body mass index. J Clin End Metab. 2008;93(1):54-60.

10. Kolesnikova LI., Madaeva IM, Semenova NV, Suturina LV, Berdina ON, Sholohov LF, Solodova EI. Pathogenic role of melatonin in sleep disorders in menopausal women. Bull Exp Biol Med. 2013;156(1):104-6.

11. Buysse DJ, Reynolds CF 3rd, Monk TH, Berman SR, Kupfer DJ. The Pittsburgh Sleep Quality Index: a new instrument for psychiatric practice and research. Psychiatry Res. 1989; 28(2):193-213.

12. Gradisar M, Lack L, Richards H, Harris S, Gallasch J, Boundy M, Johnston A. The Flinders Fatigue Scale: preliminary psychometric properties and clinical sensitivy of a new scale for measuring daytime fatigue associated with insomnia. J Clin Sleep Med. 2007;3(7):722-8.

13. Johns MW. A new method for measuring daytime sleepiness: the Epworth sleepiness scale. Sleep. 1991;14(6):540-5.

14. Gradisar MS, Lack LC, Harris JK, Richards H, Gallasch $\mathrm{J}$, Boundy M, et al. Psychometric properties of two new scales for measuring daytime functioning for insomnia. Internal Medicine Journal. 2006; 36(5):A26-A27.

15. Savard J, Simard S, Morin C. Insomnia. In: A. Nikcevic, A. Kuczmierczyk, M. Bruch (Eds). Formulation and treatment in clinical health psychology. London: Routledge; 2007.

16. Zhao ZY, Xie Y, Fu YR, Bogdan A, Touitou Y. Aging and circadian rhythm of melatonin: a cross-sectional study of
Chinese subjects $30-110 \mathrm{yr}$ of age. Chronobiol Int. 2002; 19(6):171-82.

17. Munch M, Knoblauch V, Blatter K, Wirz-Justice A, Cajochen C. Is homeostatic sleep regulation under low sleep pressure modified by age? Sleep. 2007;30(6):781-92 .

18. Münch M, Silva EJ, Ronda JM, Czeisler CA, Duffy JF. EEG sleep spectra in older adults across all circadian phases during NREM sleep. Sleep. 2010; 33(3):389-401.

19. Ivanov SV. [Menopause--a key aspect of aging: role of the pineal gland]. Adv Gerontol. 2007; 20(4):19-24. [Article in Russian].

20. Obayashi K, Saeki K, Tone N, Iwamoto J, Miyata K, Ikada Y, Kurumatani N. Lower melatonin secretion in older females: gender differences independent of light exposure profiles. J Epidemiol. 2015;25(1):38-43. doi: 10.2188/jea.JE20140035.

21. Mal'tseva LI, Gafarova EA, Garipova GKh. [The role of melatonin in regulation of gonadal function and its use in the treatment of pathological climax symptoms]. Adv Gerontol. 2007; 20(4):68-74. [Article in Russian].

22. Toffol E, Kalleinen N, Haukka J, Vakkuri O, Partonen T, Polo-Kantola P. Melatonin in perimenopausal and postmenopausal women: associations with sleep, mood, anxiety and climacteric symptoms. Menopause. 2014;21(5):493-500. doi: 10.1097/GME.0b013e3182a6c8f3.

23. Okatani Y, Morioka N, Wakatsuki A. Changes in nocturnal melatonin secretion in perimenopausal women: correlation with endogenous estrogen concentrations. J Pineal Res. 2000;28(2):111-8.

24. Walecka-Kapica E, Chojnacki J, Stępień A, WachowskaKelly P, Klupińska G, Chojnacki C. Melatonin and female hormone secretion in postmenopausal overweight women. Int J Mol Sci. 2015; 16(1):1030-42. doi: 10.3390/ijms16011030. 25. Braam W, Didden R, Smits M, Curfs L. Melatonin treatment in individuals with intellectual disability and chronic insomnia: A randomized placebo-controlled study. J Intellect Disabil Res. 2008;52(Pt 3):256-64. doi: 10.1111/j.13652788.2007.01016.x.

26. Haimov N, Lavie P, Laudon M, Herer P, Vigder C, Zisapel $\mathrm{N}$. Melatonin replacement therapy of elderly insomniacs. Sleep. 1995;18(7):598-603.

27. Duffy JF, Zeitzer JM, Rimmer DW, Klerman EB, Dijk DJ, Czeiser CA. Peak of circadian melatonin rhythm occurs later within the sleep of older subjects. Am J Physiol Endocrinol Metab. 2002; 282(2):E297-303. 